\title{
EXPERIMENTAL STUDY OF ATMOSPHERIC WATER GENERATOR UNDER LIBYAN CLIMATE
}

\author{
Abdelhafid A.Almrid \\ Mechanical Engineering Department. \\ Sabratha Engineering College, Sabratha University, Libya \\ Fadl Mustfa Alanabi \\ Mechanical Engineering Department. \\ Sabratha Engineering College, Sabratha University, Libya
}

\begin{abstract}
Drinking water is hard for people to get sometimes in Libya, during the summer, or in arid regions. The problem of water scarcity is also observed in other places due to lack of rainfall. The paper presents an experimental study of $A W G$ in Libyan climate conditions. A portable AWG (35kg) experimentally investigated in this study, different inlet airflow, humidity, and temperature to get their effects on the amount of water that can be generated by $A W G$ and energy required. The amount of generated water increased with an increase in temperature, humidity, and inlet airflow. The maximum efficiency of $A W G$ was $40.56 \%$ at temperature $21.3{ }^{\circ} \mathrm{C}$, humidity $41 \%$ airflow rate $294.84 \mathrm{~m} 3 / \mathrm{hr}$, and 1031.52 Watt input power and found that the location of dew point effect of $A W G$ productivity.
\end{abstract}

Keywords: Air, atmospheric water generator, dew point, water yield rate Humidity.

Cite this Article: Abdelhafid A.Almrid and Fadl Mustfa Alanabi, Experimental Study of Atmospheric Water Generator under Libyan Climate, International Journal of Mechanical Engineering and Technology (IJMET), 12(5), 2021, pp. 38-44.

https://iaeme.com/Home/issue/IJMET?Volume=12\&Issue=5

\section{INTRODUCTION}

Freshwater scarcity is a global issue that threatens human life, especially in arid regions. [1,2] By 2025, 3 billion people spread over fifty-two countries will face water scarcity. Drinking water supply is a big problem in several rural areas of Libya during the summer due to a shortage of rainfall and electrical resources to provide water, which forces people in this region to travel many kilometres to get water. On February 1, 2021, UNICEF expresses concern about the deteriorating WASH situation in Libya. Over 4 million people, including 1.5 million children, would face unavoidable water shortages if immediate solutions are not developed and applied. [3] 
The paper discusses atmospheric water harvesting, as an opportunity water supply in Libya. The amount of renewable water in the atmosphere is more than $12.9 * 1012 \mathrm{~m} 3$, this amount of renewable water is more than the total amount of fresh water in wetlands and rivers [4]. This water can be obtained by condensing it into drops of water using special equipment designed for this purpose. The refrigeration process is one of the most important techniques in condensation.

Fig. 1. represents a various water generation techniques [5]. The conventional compression refrigeration system is one of the alternative methods for freshwater recovery from the atmosphere, and it can provide fresh drinking water by withdrawing water from saturated atmospheric air through the Cooling condensation mechanism. In a cooling condensation-based atmospheric water generator, a compressor circulates the refrigerant into a condenser and an evaporator loop, cooling the surrounding air to dew point and causing vapor to condense. A variable-speed fan blows filtered air over the coil. The resulting water is then passed into a holding tank equipped with a washing and filtration framework to ensure that the water is pure. Atmospheric water generating technology offers 99.9\% unadulterated drinking water 365 days every year. The atmospheric water generator is an ecologically protected wellspring of maintainable water[6].

The performance of atmosphere water production is dependent on relative humidity, ambient air temperature, and compressor size, so the AWG operates more effectively when relative humidity and air temperature rise. However, the AWG will not work efficiently when the temperature decreases and humidity falls below 30\%. The cost-effectiveness of AWG is determined by the device's capacity, temperature, and local humidity, as well as the cost power per unit [7].

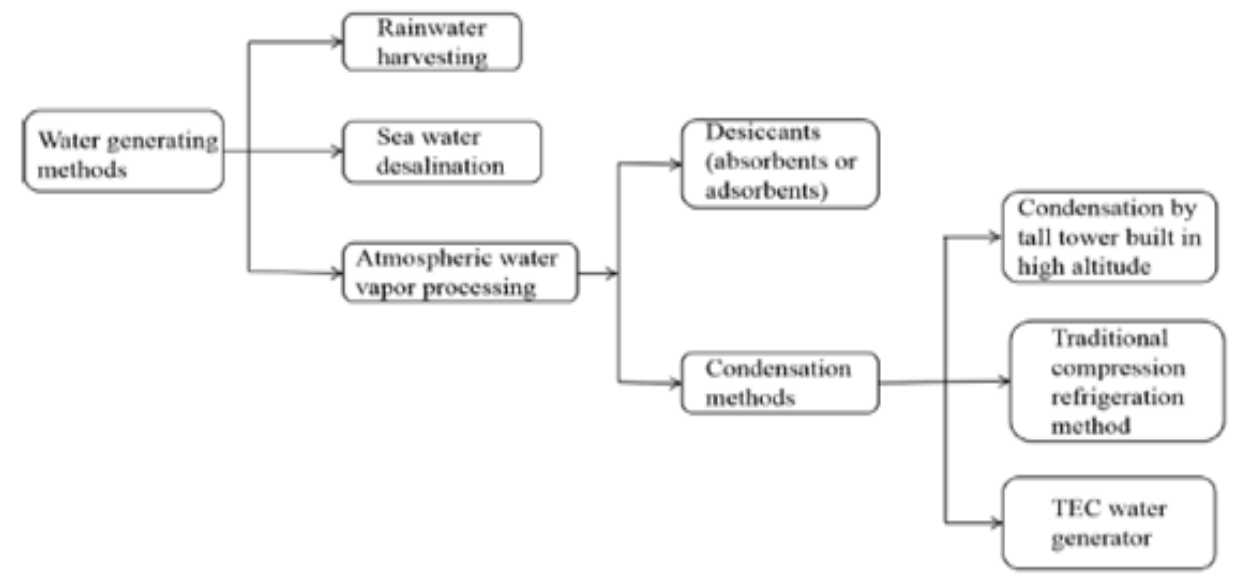

Figure 1. Classification of water generating techniques

\section{METHODOLOGY}

\subsection{Experimental Setup}

A compressor circulates the refrigerant through a condenser in a direct air cooling water generator, as seen in Fig. 2. and an evaporator coil cools the air around it. This causes vapor to condense by lowering the air temperature to its dew point. A controlled-velocity fan blows filtered air over the coil into a 0.13 -meter-long, 0.63-meter-wide duct.

Following that, the temperature of the air entering the evaporator dropped to its dew point, and several droplets condensed on the water channel. The condensed droplets grew and eventually fell outside of the unit. 


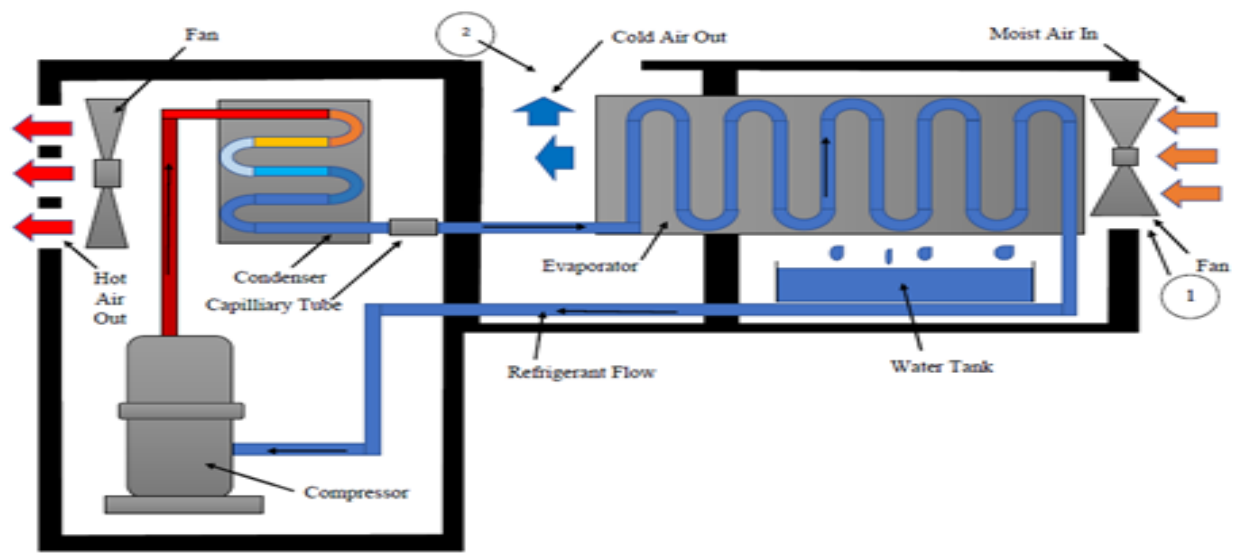

Figure 2. The diagram of structure Model

\subsection{Test Procedure}

The tests were conducted between March 21st and April 17th, 2021. And used monitoring devices such as a clamp type multimeter to measure current and voltage, an anemometer to measure airflow inlet and outlet, a thermocouple to measure airflow temperature, and a hygrograph to measure airflow humidity. Tab.l shows the testing positions for temperature, airflow rate, and relative humidity. The measured data and generated water were recorded once every hour. The specs of experimental apparatuses used are defined in Table 1.

Table 1 The specifications of experimental apparatuses used.

\begin{tabular}{|c|c|c|c|c|c|}
\hline Apparatuses & Unit & $\overline{A c c}$ & acy & Range & Purpose \\
\hline Clapometer & \begin{tabular}{l|l}
$\mathrm{A}$ & $\mathrm{V}$ \\
\end{tabular} & $\pm(2.5 \%+15 \mathrm{~d})$ & $\pm(1.0 \%+5 \mathrm{~d})$ & $400 / 600$ & $\begin{array}{l}\text { Current and voltage } \\
\text { testing }\end{array}$ \\
\hline Anemometer & $\mathrm{m} / \mathrm{s}$ & & & $0.4-30.0$ & Air flow rate testing \\
\hline Thermocouple & $\mathrm{c}$ & & & $-200-1300$ & Temperature testing \\
\hline Hygrograph & $\%$ & & & $0 \sim 99$ & Air humidity testing \\
\hline $\begin{array}{l}\text { Graduated } \\
\text { cylinder }\end{array}$ & $\mathrm{ml}$ & & & $50-500$ & Water generated testing \\
\hline
\end{tabular}

\subsection{Water Yield Prediction}

The vapor level $\left(\dot{\mathrm{m}}_{\max }\right)$ has been determined by the humidity content of air next to the AWG inlet. The air temperature and moisture of the airflow through the channel is determined to obtain the moisture content. From the absolute humidity tables, we get an approximate relationship $\left(\dot{\mathrm{m}}_{\max }\right)$ that describes the humidity Lurking in the air as a function of temperature and relative humidity.

Also, an approximate equation was obtained describing the dew point (Td) of the moist air as a function of the impulsivity humidity and temperature.

Detailed calculations [6] on the water yield are as follows:

$$
\begin{gathered}
\dot{m}_{\max }=\left(4.8+0.344 * T_{\text {in }}+9.52 * 10^{-4} * T_{\text {in }}^{2}+1.9 * 10^{-4} * T_{\text {in }}^{3}+1.835 * 10^{-6}\right. \\
\left.* T_{\text {in }}^{4}\right) R h_{\text {in }}(1) \\
\dot{m}=\dot{m}_{\text {max }} * V_{\text {in }} * A_{\text {channel }} * 3600
\end{gathered}
$$

Where $\dot{\mathrm{m}}_{\max }$ represent the maximum amount of water vapor of air, $\mathrm{g} / \mathrm{m}^{3} ; \dot{m}$ represent the maximum amount of water vapor in air, $\mathrm{ml} / \mathrm{hr}$; $\mathrm{T}_{\text {in }}$ represent the temperature of inlet air, in ${ }^{\circ} \mathrm{C}$, $\mathrm{Rh}_{\text {in }}$ represent the humidity in the inlet air, in \%; $\mathrm{V}_{\text {in }}$ represent the speed of inlet air, in $\mathrm{m} / \mathrm{s}$; $\mathrm{A}_{\text {channel }}$ represent the area of channel, in $\mathrm{m}^{2}$. 


\subsection{Dew Point Calculation}

The dew point calculated $\left(T_{d p}\right)$ by measuring the temperature and the humidity of inlet air throw the channel.

$$
\begin{gathered}
T_{d p}=-26.44+0.757 * T_{i n}+45.486 * R h_{i n}-8.124 * 10^{-5} * T_{i n}^{2}-20.257 * R h_{i n}^{2} \\
+0.278 * T_{i n} * R h_{\text {in }}
\end{gathered}
$$

Where, $\mathrm{T}_{\mathrm{dp}}$ represent the dew point ${ }^{\circ} \mathrm{C}$

\section{EXPERIMENTAL RESULTS}

\subsection{Comparison of Measured and Calculated Water Yield}

We can quantify the volume of water in the air using Eq.1 - Eq,3.

The accuracy of experimental research was validated by comparing the observed and estimated water yield rate evolution. The estimated and evaluated outcomes are depicted in Fig. 3.

It is clear from the calculated data and equation findings that the same point of maximum efficiency exists. Productivity increases with relative humidity and temperature, with the highest values at $18.3{ }^{\circ} \mathrm{C}$ and 64 percent humidity, and $21.3{ }^{\circ} \mathrm{C}$ and 41 percent humidity. The up-and-down movement of the lines shows that the relative humidity varies with temperature. The resulting difference between the calculated and observed water yield rate was nearly constant during the experiment.

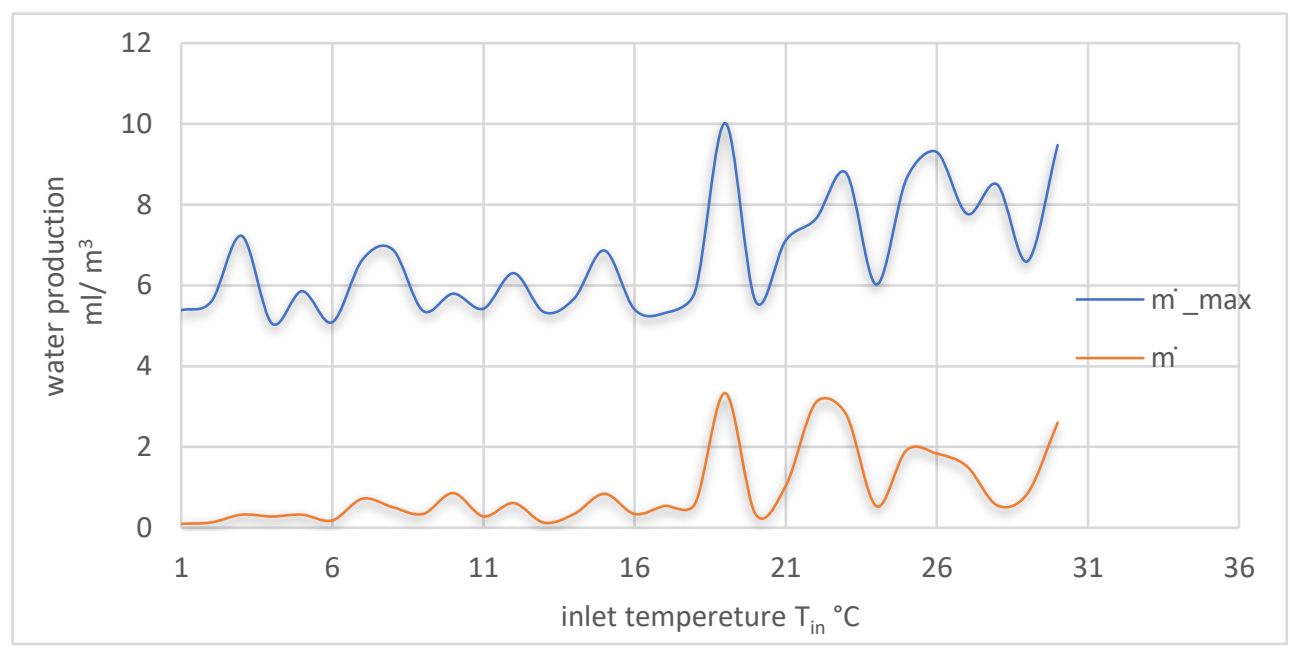

Figure 3 Comparison between the measured and calculated water yield rates

\subsection{The Impact of inlet temperature}

Fig. 4. The effect of the inlet temperature on the water production.

Fig. 4 shows that at a constant humidity of $38 \%$, the relationship between inlet temperature and estimated water yield is linear, whereas measured water productivity increases with temperature. This is due to the action of absolute humidity with temperature, in which raising the temperature to the same relative humidity increases the volume of vapor lurking in the air. 


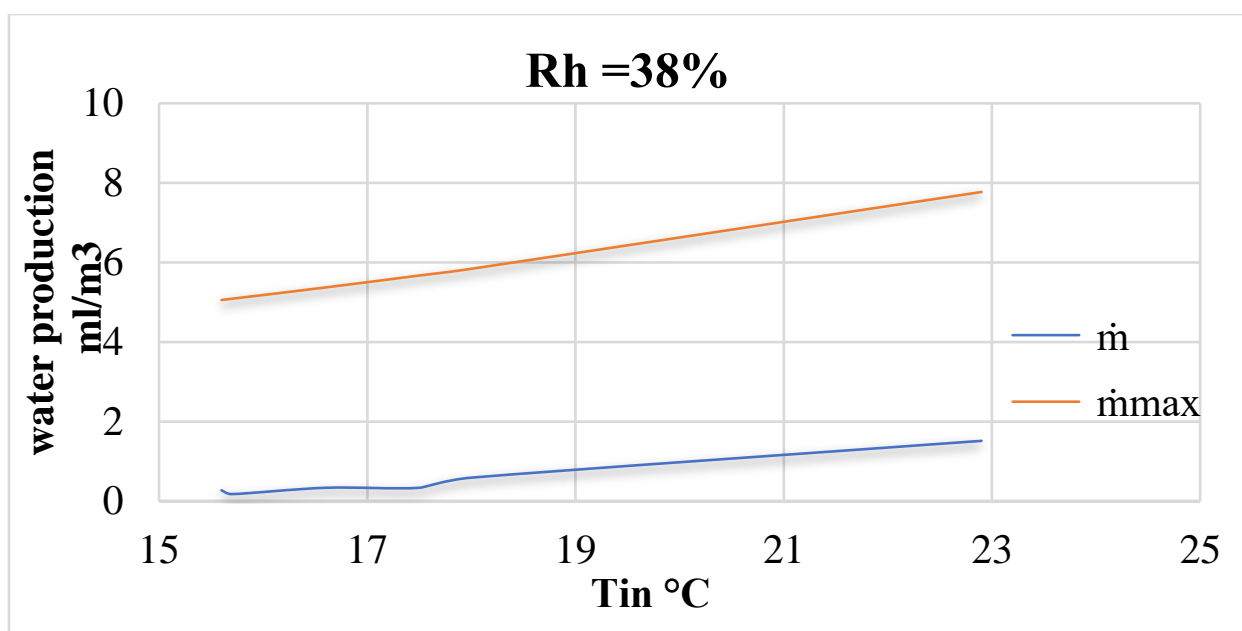

Figure 4. The effect of the inlet temperature on the water production

\subsection{The Impact of Airflow}

Fig.5 shows that when the inlet airflow increases but the temperature does not, water productivity increases in both the measured water yield and the AWG unit at constant humidity $\mathrm{Rh}=38$ percent. Now, we can see in the measured water yield that as the temperature rises from $15.6^{\circ} \mathrm{C}$ to $22.9^{\circ} \mathrm{C}$, the proportion of water in the air increases to 53.64 percent. At the same time, in AWG, the rising ratio of water productivity reaches 447.3 percent, which is a very high increasing ratio, and when temperature decreases from $22.9 \mathrm{co}$ to $18 \mathrm{co}$, the ratio of estimated water yield decreases to 24.83 percent, while the ratio of measured volume of water from AWG decreases to 60.92 percent, which is a small ratio decrease when compared to the ratio of rise.

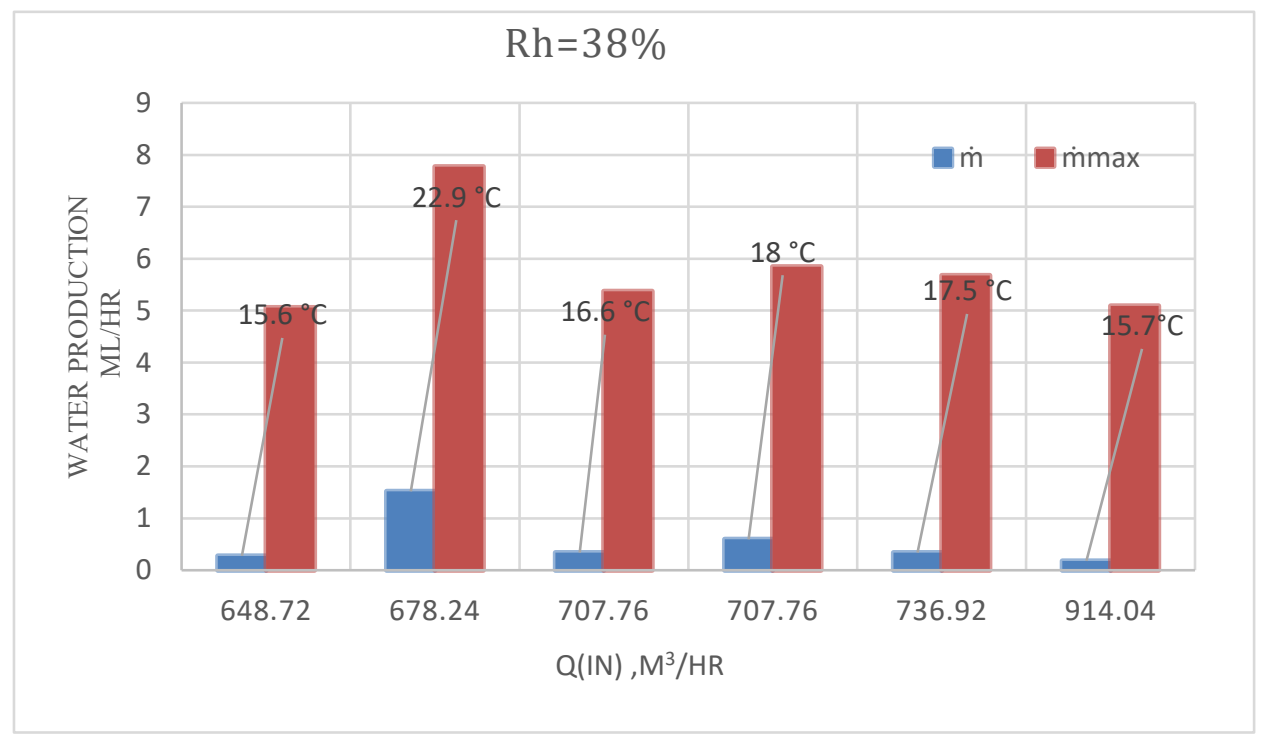

Figure 5. The effect of inlet airflow on the water production

\subsection{The Impact of Humidity on Dew Point}

Fig. 6 shows that humidity has a large influence on the dew point, because as the humidity rises, the dew point rises, and temperature changes have little effect on the dew point when the humidity is not constant. In this case, we have two points with a humidity of $36 \%$ but temperatures of $17.4^{\circ} \mathrm{C}$ and $17.6^{\circ} \mathrm{C}$, so the dew point rises when the temperature rises. 


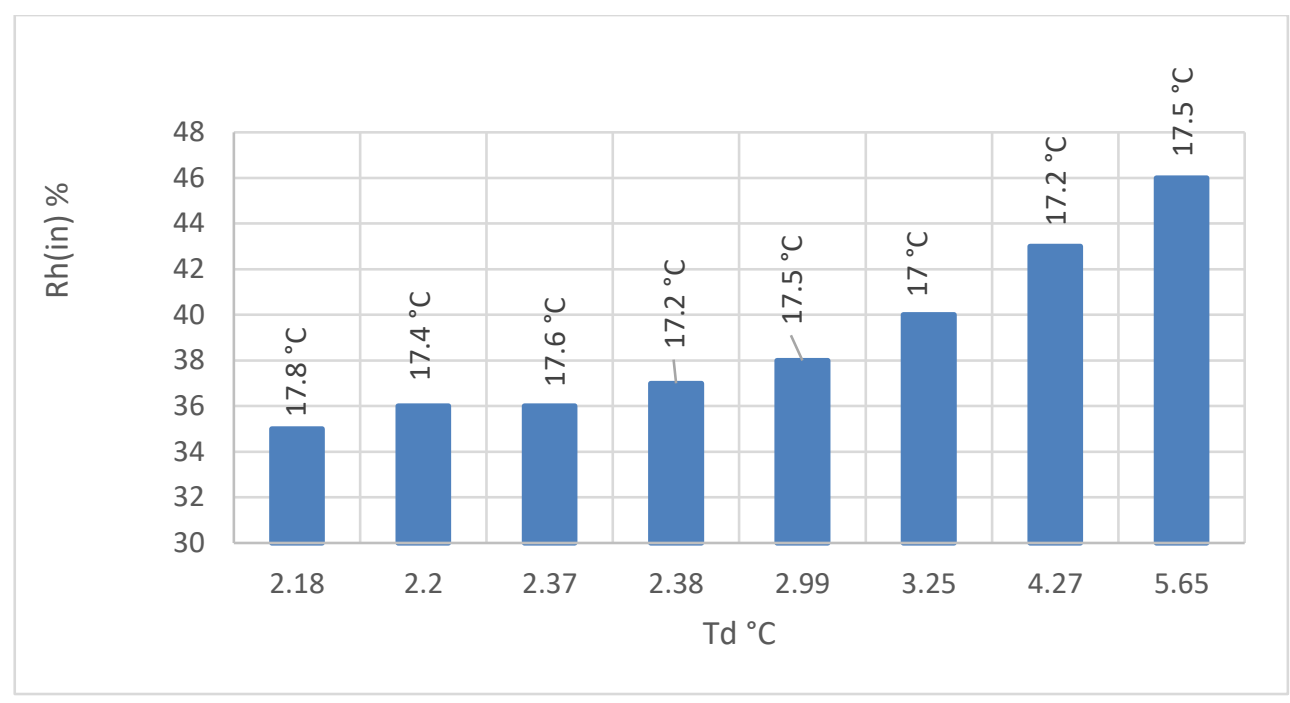

Figure 6. The effect of humidity on dew point

\subsection{Energy Requirements and Production}

Figure (7) shows a bar chart illustrating the energy required for water production in (Watt $/ \mathrm{ml})$. It can be seen that when productivity is low, energy is relatively high, and vice versa. The energy required to produce one milliliter of water has the lowest value of $0.56 \mathrm{Watt}$ and the highest value of 17.2 Watt.

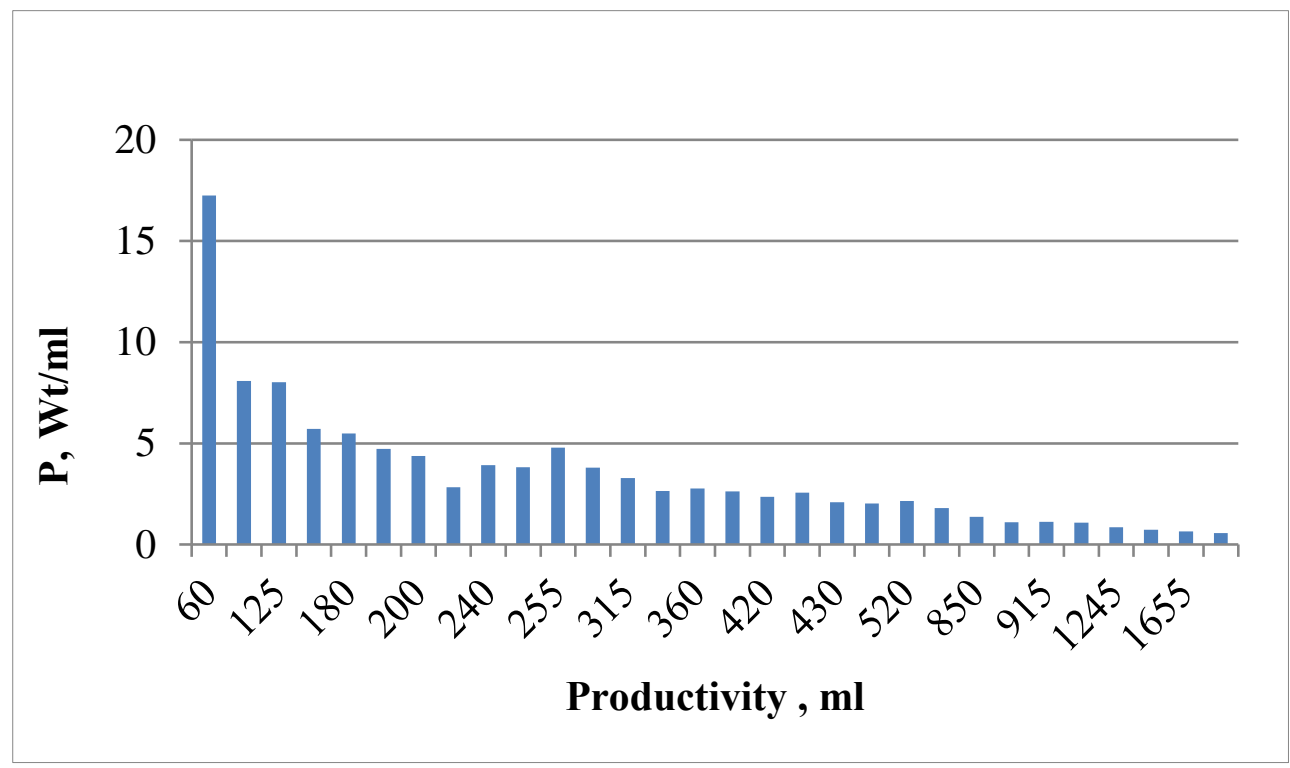

Figure 7. The energy requirements for water production

\section{CONCLUSION}

The effectiveness of atmospheric moisture harvesting (AMH) through direct air cooling, as well as its energy consumption, are determined by the thermodynamic state of the ambient air.In dry areas where water is scarce, the ambient air conditions are frequently less favorable for AMH by direct electric cooling (low MHI) and impose high energy demands per unit water production. The system was experimentally investigated at different inlet air flow rates, temperatures and humidity. 
The inlet air approaches the dew point at or after the excite, which reduces AWG effectiveness and is the primary explanation for the large gap between AWG measured and estimated results, but at higher temperatures and humidity rates, AWG efficiency of removing water from humid air increases because the dew point becomes closer to the inlet.

The ability of air to contain vapor increases with increasing temperature and humidity, increasing the efficiency of the water generator while decreasing energy consumption.

More efforts will be needed in the future to refine the system configuration in order to increase the area of cooling surface for increased water productivity.

\section{REFERENCES}

[1] Mekonnen, M. M., Hoekstra, A. Y., "Four Billion People Facing Severe Water Scarcity". Sci. Adv. 2016, 2, No. e1500323.

[2] Johnson, N., Revenga, C., Echeverria, J., "Managing Water for People and Nature". Science 2001, 292, 1071-1072

[3] https://www.unicef.org/media/media_59666.html.

[4] Dia Milania, Abdul Qadira, Anthony Vassalloa, Matteo Chiesab, Ali Abbasa, "Experimentally validated model for atmospheric water generation using a solar assisted desiccant dehumidification system” Energy and Buildings, Volume 77, July 2014, Pages 236-246.

[5] Wei He, Pengkun Yu, Zhongting Hu, Song Lv, Minghui Qin 3 and Cairui Yu. "Experimental Study and Performance Analysis of a Portable Atmospheric Water Generator", Energies, $2020,13,73$.

[6] T. Anbarasu*, S. Pavithra†* M. E, "Vapour Compression Refrigeration System Generating Fresh Water from Humidity in the Air", International Conference on Sustainable Energy and Intelligent Systems (SEISCON 2011), 2011 p. 75 - 79.

[7] Thermodynamics of humid air Markku J. Lampinen, "Thermodynamics of humid air "Tech. Rep. Ene-39.4027-Mass Transfer P, Department of Energy Technology, Aalto University (2015). 